\title{
Avaliação das críticas relatadas na literatura aos métodos de custeio: percepção dos gestores de médias e grandes empresas industriais catarinenses
}

\author{
Rodrigo Angonese" \\ Araceli Farias de Oliveira** \\ Jorge Eduardo Scarpin ${ }^{* * *}$
}

Resumo

Mudanças no ambiente de negócios exigem da contabilidade de custos uma nova postura a fim de atender as necessidades dos gestores. Métodos de custeio que até pouco tempo eram considerados adequados, agora, são considerados ultrapassados, pois não estão adequados ao atual ambiente de negócios. O objetivo geral desta pesquisa é verificar com gestores de médias e grandes empresas industriais do estado de Santa Catarina se eles reconhecem as críticas encontradas na literatura sobre os métodos de custeio. Para tal, a pesquisa caracterizou-se como descritiva, quantitativa e de levantamento. Os resultados mostram que, de modo geral, as críticas atribuídas aos métodos de custeio são reconhecidas pelos gestores. Aliado a isso, percebe-se também que, embora sejam reconhecidas, as críticas não se constituem impedimento para a utilização do método, mas, sim, uma limitação.

Palavras-chave: Críticas. Métodos de custeio. Custos.

* Doutor em Ciências Contábeis e Administração. Professor na Universidade de Passo Fundo. E-mail: rangonese@gmail.com

** Mestra em Ciências Contábeis. Professora na Universidade do Sul de Santa Catarina. E-mail: araceli.oliveira@unisul.br

**** Doutor em Controladoria e Contabilidade. Professor na Universidade Federal do Paraná. E-mail: jorge.scarpin@ufpr.br

http://dx.doi.org/10.5335/rtee.v21i45.6192

Submissão: 29/05/2015. Aceite: 14/12/2015 


\section{Introdução}

As situações mudam. Essa afirmativa é provada pelos registros históricos. Não se pode pensar que o ambiente empresarial de alguns anos atrás funciona da mesma maneira que o ambiente em que as empresas estão inseridas nos dias de hoje. Esse processo de mudança exige flexibilidade das empresas para a adaptação da gestão. Ferramentas gerenciais que até pouco tempo atendiam às necessidades dos gestores, atualmente podem estar deixando a desejar.

No tocante ao ambiente empresarial ligado à área de produção, muitas coisas mudaram. Desde a revolução industrial, houve um aperfeiçoamento contínuo na linha de produção com a implementação de novas tecnologias produtivas. Essas implementações alteraram gradativamente o processo de produção, que paulatinamente promoveu a substituição da mão de obra por máquinas, robôs, computadores.

Essa substituição acarretou uma mudança na composição dos custos dos produtos. Se antes prevaleciam os custos com mão de obra sobre os custos indiretos de produção, atualmente, em muitas organizações, a situação é inversa. Essa nova configuração dos custos de produção exige uma evolução dos métodos de custeio utilizados pelas empresas (COGAN, 1994 ; PEREZ JR.; OLIVEIRA; COSTA, 2001).

Além disso, percebe-se que o ambiente em que as empresas operam também mudou significativamente. A concorrência aumentou, o preço diminuiu, a margem de lucro é menor, novas tecnologias auxiliam a produção, como é o caso da busca pela qualidade total e a filosofia de gerenciamento de estoques nominada Just-in-time ${ }^{1}$ (PEREZ JR.; OLIVEIRA; COSTA, 2001). Por conseguinte, a contabilidade de custos também teve de se adaptar e inovar para atender à necessidade desse novo ambiente.

Nesse contexto, novos métodos de custeio foram desenvolvidos, embora outros métodos de custeio já existentes continuaram sendo utilizados. A literatura sobre 0 tema disponibiliza para cada método de custeio um conjunto de críticas, vantagens e desvantagens.

Beuren, Souza e Raupp discorrem sobre a postura das organizações diante das mudanças do ambiente quando mencionam que:

[...] a análise das informações de custos é relevante para o processo decisório nas organizações, tanto no momento da definição do preço de venda, como na gestão dos custos e em decisões que têm como resultado o incentivo aos produtos mais rentáveis. Num ambiente cada vez mais competitivo, as organizações são obrigadas a evoluir e apreender constantemente, além de se empenhar na busca de melhores informações para o gerenciamento de seus custos $(2004$, p. 3$)$. 
Perceber in loco se as desvantagens e críticas aos métodos de custeio, publicadas nos meios científicos, são reconhecidas pelos usuários contribui na medida em que permite a identificação das principais críticas. Diante dos resultados, podem ser desenvolvidos estudos complementares que contemplem identificar, mitigar ou eliminar os fatores que levam às críticas, melhorando assim, dentro do possível, o método de custeio.

Neste estudo, há o cruzamento entre as informações sobre os métodos utilizados atualmente e o conhecimento das limitações de cada método. $\mathrm{O}$ cruzamento dessas informações pode indicar perspectivas a fim de verificar se métodos considerados ultrapassados continuam sendo utilizados ou não. A partir das críticas traçadas aos diversos métodos de custeio, apresenta-se o seguinte problema de pesquisa: As críticas realizadas aos métodos de custeio são reconhecidas pelos gestores das médias e grandes empresas industriais de Santa Catarina que os utilizam?

Paralelamente a esse questionamento, o objetivo geral da pesquisa é verificar com gestores de médias e grandes empresas industriais do estado de Santa Catarina se eles reconhecem as críticas encontradas na literatura sobre os métodos de custeio. Os objetivos específicos incluem: a) caracterizar a amostra respondente; b) identificar quais são as críticas realizadas aos métodos de custeio; c) identificar quais são os métodos de custeio utilizados pelas empresas respondentes; d) identificar se os dirigentes reconhecem as críticas realizadas aos métodos de custeio.

Pretende-se, com este estudo, verificar até que ponto os gestores reconhecem as críticas, a fim de procurar evidências empíricas que possam ampliar o conhecimento sobre as correntes teóricas que tratam da utilização dos métodos de custeio nas organizações.

Este artigo está estruturado em cinco seções, iniciando com esta introdução. Na sequência, faz-se uma descrição dos principais conceitos e estudos relacionados ao tema, depois, descreve-se o método e os procedimentos da pesquisa. Em seguida, são apresentados os resultados da tabulação e da análise dos dados e, por fim, as considerações finais.

\section{Referencial teórico}

Nesta seção são apresentados os principais conceitos envolvidos no estudo. Adicionalmente, procura-se demonstrar, a partir da literatura existente, as críticas relacionadas a cada método de custeio. 


\subsection{Métodos de custeio}

A apuração dos custos nas organizações ocorre a partir da aplicação de um sistema de custos. A adoção de um sistema de custeio para auxiliar na gestão da empresa é fundamental. Babad e Balachandran mencionam que o objetivo de qualquer sistema de gerenciamento de custos "[...] é prover informações relevantes e em tempo para o gerenciamento. Esta informação subsidiará um melhor gerenciamento dos recursos da companhia na produção dos produtos ou provisão dos serviços, e aumenta a competitividade em termos de custos, qualidade e rentabilidade" (1993, p. 563).

Dentre os principais sistemas de custos, pode-se relacionar o custeio por absorção, o custeio pleno ou integral, o custeio direto ou variável, o custeio baseado em atividades $(\mathrm{ABC})$, o custeio padrão, o custeio meta, o custeio baseado em unidade de esforço de produção (UEP).

\subsubsection{Custeio absorção}

Segundo Pereira Filho e Amaral, o sistema de custeio por absorção "é aquele que inclui todos os custos indiretos de fabricação de certo período em suas diferentes atividades industriais, sejam produtos, processos ou serviços". Os autores complementam, mencionando que a finalidade principal "é mensurar o custo total (direto e indireto) de cada objeto de custeio" (1998, p. 8).

Diversos autores colocam algumas vantagens e desvantagens na utilização desse método. Segundo Beuren, Sousa e Raupp, o custeio por absorção:

[...] não está preocupado em fazer distinção entre custos fixos e variáveis. Sua premissa fundamental é separar custos e despesas. Sendo que os custos são apropriados aos produtos, para, no momento da venda, serem confrontados com as receitas geradas, e as despesas são lançadas diretamente no resultado do período (2004, p. 6).

Martins (2003) menciona que, teoricamente, a distinção entre custo e despesa é fácil, entretanto, na prática, não é tão simples. O autor explica que "é comum encontrarmos uma única administração, sem a separação da que realmente pertence a fábrica" (2003, p. 39). Essas situações acabam por caracterizar a subjetividade do custeio por absorção.

Pereira Filho e Amaral apresentam algumas vantagens e desvantagens sobre o sistema de custeio absorção: 
a) Atende as exigências legais e se ajusta adequadamente aos sistemas de custos integrados à contabilidade financeira; b) As bases de rateio utilizadas para distribuir os gastos entre os departamentos nem sempre são objetivas e podem distorcer os resultados, penalizando alguns produtos em detrimento de outros; c) Permite a mensuração do custo por centro de custos, uma vez que a sua aplicação exige a organização contábil nesse sentido, permitindo a utilização de custos para fins de controle; d) Por absorver todos os custos de produção, permite a mensuração do custo de cada produto ou serviço, o qual, entretanto, pode apresentar distorções em função das bases de rateio utilizadas (1998, p. 8).

Maher (1997) trata sobre algumas críticas relacionadas ao sistema de custeio absorção, e menciona que o custeio absorção trata os custos fixos como se fossem custos unitários e que, em comparação com outros sistemas de custeamento, como o custeio variável, o custeio absorção oferece uma quantidade inferior de informações. Ainda, o autor afirma que o custo fixo unitário pode induzir a erros, devido ao fato de serem variáveis em relação ao volume de produção. Na sequência, será apresentada a abordagem para a compreensão do custeio pleno.

\subsubsection{Custeio pleno}

Segundo Machado, o custeio pleno "é aquele em que todos os custos e despesas de uma entidade são levados aos objetos de custeio, normalmente unidades de produtos" (2005, p. 33). É conhecido no Brasil também como custeio RKW, sigla de Reichskuratorium für Wirtschaftlichtkeit. Martins contribui, afirmando que esse sistema "consiste no rateio não só dos custos de produção como também de todas as despesas da empresa, inclusive financeiras, a todos os produtos" (2003, p. 220).

Machado afirma que "[...] uma das desvantagens desse método é que ele não faz a distinção entre custos fixos e variáveis. Uma empresa que adota esse método, desconhecendo os custos variáveis, tende a rejeitar as encomendas que não cubram, pelo menos, os custos totais do produto" (2005, p. 37). Percebe-se que o custeio pleno diferencia-se do custeio absorção, pois o primeiro não faz distinção entre custos e despesas.

\subsubsection{Custeio direto ou variável}

Pereira Filho e Amaral aduzem que o sistema de custeio variável "é aquele em que só se inclui no custo das operações, produtos, serviços e atividades, os custos diretos e variáveis. [...] Os custos fixos referentes a fabricação, assim como as despesas de vendas e administrativas serão debitadas diretamente ao resultado do período" (1998, p. 8). 
Martins define custeio variável como aquele em que "só são alocados aos produtos os custos variáveis, ficando os fixos separados e considerados como despesas do período, indo diretamente para o resultado; para os estoques só vão, como consequência, custos variáveis" (2003, p. 198).

Da mesma forma que outros sistemas de custeio, o custeio direto ou variável também apresenta algumas vantagens e desvantagens. Pereira Filho e Amaral apresentam algumas vantagens e desvantagens sobre o sistema de custeio absorção:

a) É orientado basicamente para o aspecto gerencial por permitir a apuração da lucratividade real de cada produto ou serviço, não se adequando, entretanto, às exigências legais; b) Enfoca basicamente o custo unitário de produção, uma vez que utiliza, em sua composição, gastos que variam a cada unidade produzida; com isso, isola a influência do volume sobre o custo; c) Não envolve critérios de rateio e distribuição de gastos entre departamentos; d) Requer a distribuição dos custos e despesas em fixas e variáveis, o que demanda uma estrutura de classificação de gastos adequada para tal finalidade; e) Seu uso deve ser avaliado em maior detalhe em empresas intensivas em capital (ativo permanente elevado), pois, nesses casos, deve haver a preocupação com a 'absorção' dos custos fixos, especialmente no que diz respeito à depreciação $(1998$, p. 9).

Percebe-se, portanto, que as principais críticas em relação ao método de custeio direto ou variável encontram-se no enfoque de curto prazo, na subjetividade de algumas contas, para classificação em gastos fixos e variáveis, e no tratamento do custo fixo diretamente para o resultado.

\subsubsection{Custeio baseado em atividades}

Bornia afirma que "[...] a ideia básica do $\mathrm{ABC}$ é tomar os custos de várias atividades da empresa e entender seu comportamento, encontrando bases que representem as relações entre os produtos e essas atividades" (2002, p. 121). Quanto ao custeio ABC, Nakagawa afirma que "[...] trata-se de uma metodologia desenvolvida para facilitar a análise estratégica de custos relacionados com as atividades que mais impactam o consumo de recursos de uma empresa" (2000, p. 40).

Ainda segundo Nakagawa, o objetivo do custeio ABC diferencia-se dos demais métodos, pois "[...] a quantidade, a relação de causa e efeito e a eficiência e eficácia com que os recursos são consumidos nas atividades mais relevantes de uma empresa constituem o objetivo da análise estratégica de custos do ABC" (2000, p. 40).

Frezatti et al. contribuem com o assunto afirmando que o custeio baseado em atividades "tem por objetivo principal fornecer os elementos para isso; trata-se portanto, de um método de análise de custos, principalmente de overhead, focado nos 
processos e nas atividades mais relevantes nas organizações" (2009, p. 91). Quando os autores mencionam que o objetivo principal do $\mathrm{ABC}$ é fornecer elementos para isso, referem-se à preocupação e à necessidade de os administradores de empresas saberem em que os recursos são utilizados. A preocupação é reforçada pela crescente participação dos custos de overhead (custo das atividades de natureza preponderantemente administrativa, que compreende as despesas da administração geral e do custo das atividades de apoio ao processo produtivo, tais como planejamento e controle da produção, gerência, supervisão, controle da qualidade, logística, etc.). Mishra e Vaysman aludem que:

[...] o argumento básico para a superioridade do ABC é que, enquanto sistemas de custeio tradicionais são muito menos dispendiosos para implementar, esses sistemas podem produzir consideráveis distorções no custo dos produtos. O mix de produção, preço, controle de custos, e outras decisões tomadas pelos gerentes utilizando estes números de custos distorcidos, podem levar a severos prejuízos no longo prazo (2001, p. 620).

Como qualquer método de custeio, existem vantagens e desvantagens identificadas na implementação e utilização desse método. De acordo com Frezatti et al.:

[...] sob a ótica do processo gerencial, o Custeio por Atividades pode ser um instrumento importante, sobretudo se utilizado em conjunto com um sistema de padrões e orçamentos integrado a uma contabilidade eficiente e eficaz. Isso porque o $\mathrm{ABC}$, além de propiciar uma alocação de custos indiretos mais criteriosa - e, nesse aspecto, é considerado uma espécie de evolução do Custeio por Absorção -, também proporciona informações que fornecem as bases para a melhoria dos processos, identificação e eliminação de atividades desnecessárias e a minimização de desperdícios. Neste último aspecto reside sua interface com a Gestão Baseada em Atividades (ABM, de Activity-Based Management) (2009, p. 91).

Algumas das críticas para o custeio baseado em atividades, na visão dos autores, referem-se ao fato de que:

[...] alguns fatores podem limitar, ou até inviabilizar, sua eficácia, como, por exemplo: dificuldade na identificação dos direcionadores de custos, necessidade de coletar muitos dados manualmente, quantidade excessiva de atividades, criação de sistemas adicionais, planilhas de time sheets trabalhosos etc. (2009, p. 91).

Nakagawa (2000) menciona que, embora contribua em termos de acurácia e utilidade informativa, o sistema de custeamento $\mathrm{ABC}$ poderá ser prejudicado pela grande quantidade de dados que ficam disponíveis diariamente.

Corroborando a esse respeito, Cogan (1994) informa que, em alguns casos, o $\mathrm{ABC}$ pode não ser aplicável na prática, pois exige um número excessivo de informações gerenciais que podem inviabilizar sua aplicação. Conforme o autor, em 
uma fábrica pode-se identificar muitas atividades e, nesses casos, o custeamento $\mathrm{ABC}$ seria impraticável devido à complexidade envolvida na sua operação. $\mathrm{O}$ autor complementa as críticas ao custeamento $\mathrm{ABC}$, afirmando que em empresas que têm um número elevado de produtos, a aplicabilidade do sistema $\mathrm{ABC}$ também ficaria comprometida, visto que provavelmente, além do elevado número de produtos, haveria um elevado número de atividades e direcionadores. A complexidade do método de custeio comprometeria sua operacionalidade.

Há estudos que apontaram a complexidade de operação do sistema de custeamento por atividades como uma de suas principais críticas. Beuren e Roedel, em estudo realizado nas duzentas maiores empresas do estado de Santa Catarina, apontaram que:

[...] a complexidade da implantação e operação do sistema, a dificuldade de manutenção, além do alto custo para a sua implantação e a subjetividade das informações sobre a distribuição dos custos indiretos foram as razões pelas quais as empresas decidiram não utilizar o sistema $\mathrm{ABC}$ (2002, p. 17).

Miranda et al. (2007) pesquisaram a utilização do custeio ABC em hospitais universitários e de ensino brasileiros. Entre os principais resultados, destaca-se a crítica de que os sistemas de custos atuais dos hospitais têm poucas condições de fornecer informações úteis à gestão. Na mesma pesquisa, as principais causas apresentadas para o não uso do sistema $\mathrm{ABC}$ foram porque o sistema utilizado atende às necessidades da organização e o custeio baseado em atividades é muito complexo.

Em pesquisa realizada por Khoury e Ancelevicz:

[...] cerca de $28 \%$ das empresas pesquisadas estavam avaliando o Sistema de Custos ABC principalmente por considerarem que esse sistema proporcionaria melhor discernimento das causas de aumento ou redução dos custos, bem como maior acurácia, sobretudo para apreçamento de produtos e serviços. No entanto, $9 \%$ das empresas decidiram não utilizar o ABC, sendo que mais de um quarto dessas empresas justificaram como principais razões para não o adotarem a complexidade e o alto custo de implantação (1999, p. 56).

Reyhanoglu também menciona algumas críticas em relação ao custeio $\mathrm{ABC}$, como "dificuldades de implementação, altos custos de implementação, resistência por parte dos funcionários, informações fora do tempo, dificuldade de obter informações e informações não confiáveis oferecidas" (2004, p. 11).

Verifica-se que, como em qualquer método, há vantagens e desvantagens na implementação e operação do custeio $\mathrm{ABC}$. As críticas atribuídas a esse custeio são normais e decorrentes de linhas de pensamento divergentes. Entretanto, cabe verificar se as críticas motivadas ao método são reconhecidas pelos gestores no processo de gestão. 


\subsubsection{Custo-meta}

Segundo Moro, o conceito de custo-meta ou custo-alvo trata do:

[...] objetivo de custo que se tem para um produto novo ou modificado, obtido através da diferença aritmética entre o preço máximo que o mercado está disposto a pagar por esse produto e a margem de lucro que se necessita obter para que se garanta a remuneração do capital aplicado na empresa e sua sobrevivência futura (2003 apud BEBER et al., 2004, p. 2).

Portanto, o custo-meta acaba por configurar-se como um instrumento gerencial voltado para o futuro da organização, que procura verificar a viabilidade econômica financeira da produção de determinado produto a partir do preço oferecido pelo mercado.

\subsubsection{Custo padrão}

O custo padrão, de acordo com Matz, Curry e Frank, "é o custo cientificamente predeterminado para a produção de uma única unidade, ou um número de unidades do produto durante um período específico no futuro imediato" (1987, p. 532).

Beuren, Sousa e Raupp entendem que "[...] o custo padrão é o custo planejado de um produto, segundo condições de operação correntes e/ou previstas. Baseia-se nas condições normais ou ideais de eficiência e volume, especialmente com respeito à despesa indireta de produção" (2004, p. 7).

Sendo assim, existe nesse processo uma estimativa dos custos que deve se realizar no futuro. Sobre a importância de se conhecer antecipadamente uma estimativa de custos, Lederer et al. mencionam que uma estimativa "auxilia a justificar custos para propósitos individuais, para acompanhar o seu desenvolvimento, controle e monitoramento do progresso, e para avaliar a qualidade do processo da estimativa" (1990, p. 159). Portanto, o custo padrão contribui para a redução do desperdício, uma vez que permite identificá-los pelas diferenças encontradas entre os custos planejados/estimados e os custos reais.

\subsubsection{Unidade de esforço de produção}

Segundo Bornia, “[...] o método da UEP baseia-se na unificação da produção para simplificar o processo de controle de gestão. A mensuração do desempenho da empresa é feita por meio de custos e medidas físicas de eficiência, eficácia e produtividade" (2002, p. 139). 
Já de acordo com Martins, o método UEP “consiste na construção e utilização de uma unidade de medida de esforços e recursos aplicados na produção de vários produtos. Essa medida deve ser homogênea, de forma que possa servir de denominador comum a todos os produtos" (2003, p. 312).

De modo geral, o método UEP procura identificar o quanto um produto consome de unidade de esforço de produção em relação aos demais.

\subsection{Críticas aos principais métodos de custeio na literatura}

Para melhor entendimento das críticas e desvantagens atribuídas aos métodos de custeio, o Quadro 1 apresenta um resumo geral dos principais métodos e críticas que lhes são atribuídos.

Quadro 1 - Resumo das críticas atribuídas aos principais métodos de custeio

\begin{tabular}{|c|c|}
\hline Método & Críticas \\
\hline $\begin{array}{l}\text { Departamentalização, } \\
\text { centro de custos, } \\
\text { custeio absorção e } \\
\text { absorção pleno }\end{array}$ & $\begin{array}{l}\text { Prejudica a tomada de decisão sobre aceitar ou não uma encomenda, produzir ou } \\
\text { comprar determinado componente, etc. (MARTINS, 2003; MACHADO, 2005). } \\
\text { Oferece uma gama de dados inferiores a outros sistemas, como o custeio variável } \\
\text { (MAHER, 1997). } \\
\text { Prejudica a tomada de decisão, pois envolve a distribuição arbitrária dos demais gas- } \\
\text { tos de fabricação, como aluguel, depreciação, material de limpeza, etc. (PEREIRA } \\
\text { FILHO; AMARAL, 1998). } \\
\text { Os custos apurados são influenciados por um maior ou menor volume de produção } \\
\text { (MAHER, 1997). } \\
\text { Trata os custos fixos de fabricação como se fossem unitários (MAHER, 1997). } \\
\text { Não faz distinção entre custos fixos e variáveis (BEUREN; SOUSA; RAUPP, 2004; } \\
\text { MACHADO, 2005). } \\
\text { Método comprometido, pois não há como classificar de modo claro quais são os } \\
\text { custos fixos e variáveis (PEREIRA FILHO; AMARAL, 1998). } \\
\text { Orientado mais para o aspecto gerencial (PEREIRA FILHO; AMARAL, 1998; MAR- } \\
\text { TINS, 2003). } \\
\text { Como considera apenas gastos variáveis, isola a influência do volume sobre o custo } \\
\text { (PEREIRA FILHO; AMARAL, 1998). } \\
\text { Atende somente a necessidades de informação para um curto prazo (MARTINS, } \\
\text { 2003). } \\
\text { No custeio baseado em atividades, os critérios de distribuição dos gastos de difícil } \\
\text { alocação, como aluguel, depreciação, etc., são aleatórios (REYHANOGLU, 2004). } \\
\text { O custeio baseado em atividades é muito complexo, de difícil manutenção e custoso } \\
\text { (MISHRA; VAYSMAN, 2001; FREZATTI et al., 2009; COGAN, 1994; BEUREN; RO- } \\
\text { EDEL, 2002). } \\
\text { É inviável sua aplicabilidade devido ao grande número de atividades presente na } \\
\text { empresa (COGAN, 1994). }\end{array}$ \\
\hline
\end{tabular}

Fonte: elaboração dos autores com base nos dados da pesquisa. 
O Quadro 1 mostra uma síntese das críticas que são encontradas na literatura aos principais métodos de custeio. Outros métodos, como o custo-meta, o custo padrão e o de unidade de esforço de produção, embora reconhecidos, não são frequentemente utilizados pelas organizações (RECKZIEGEL; SOUZA; DIEHL, 2007; SOUZA; LISBOA; ROCHA, 2003; ALMEIDA; SANTOS, 2007; BEUREN; SOUZA; RAUPP, 2004).

Na próxima seção, serão apresentados os procedimentos metodológicos que nortearam a elaboração deste estudo.

\section{Procedimentos metodológicos}

Quanto à classificação metodológica, no que se refere aos seus objetivos, a presente pesquisa classifica-se como descritiva. Uma vez que, segundo Roesch:

[...] se o propósito do projeto é obter informações sobre determinada população: por exemplo, contar quantos, ou em que proporção seus membros tem certa opinião ou característica, ou com que frequência certos eventos estão associados entre si, a opção é utilizar um estudo de caráter descritivo (1999, p. 130).

De acordo com Hair Jr. et al., a pesquisa descritiva "tem seus planos estruturados e especificamente criados para medir as características descritas em uma questão de pesquisa" (2005, p. 85).

Quanto aos procedimentos, este estudo foi classificado como levantamento, que, segundo Gil, "se caracteriza pela interrogação direta das pessoas cujo comportamento se deseja conhecer" (1999, p. 73). Raupp e Beuren mencionam que "[...] os dados referentes a esse tipo de pesquisa podem ser coletados com base em uma amostra retirada de determinada população ou universo que se deseja conhecer" (2009, p. 85).

Já quanto à abordagem do problema, classifica-se como quantitativa. De acordo com Richardson, estudos quantitativos:

[...] como o próprio nome indica, caracteriza-se pelo emprego da quantificação tanto nas modalidades de coleta de informações, quanto no tratamento dessas, através de técnicas estatísticas, desde as mais simples, como percentual, média, desvio-padrão, às mais complexas, como coeficiente de correlação, análise de regressão, etc. (1989, p. 29).

Para a coleta de dados foi utilizado o questionário. Colauto e Beuren definem questionário como um "instrumento de coleta de dados constituído por uma série 
ordenada de perguntas que devem ser respondidas por escrito pelo informante, sem a presença do pesquisador" (2009, p. 130).

A população objeto do estudo foi composta pelos gestores das médias e grandes empresas industriais do estado de Santa Catarina. O número de médias empresas nesse estado é de 574 estabelecimentos. De acordo com dados do segundo cadastro da Federação das Indústrias do Estado de Santa Catarina, conforme dados do Guia Web da Indústria de Santa Catarina (FIESC, 2010), considera-se média empresa aquelas com mais de cem e menos de 499 empregados. Já o conceito de grande empresa, de acordo com o mesmo cadastro, refere-se àquelas com número igual ou superior a quinhentos funcionários. O total de empresas consideradas grandes ficou em 175. Portanto, a população do estudo totalizou 749 empresas, para as quais foi enviado o questionário elaborado para a pesquisa.

A escolha das empresas de médio e grande porte industriais baseou-se no pressuposto de que essas empresas, provavelmente, eram as que utilizavam um sistema de custeamento no seu processo de gestão. Também o total de empresas proporcionaria um bom volume de questionários enviados, aumentando as chances de retorno de um volume suficiente para a elaboração das análises dos dados.

Segundo Witt, “[...] todo instrumento de pesquisa após elaborado, necessita ser aplicado a título experimental, antes de sua utilização de fato; é feita por assim dizer, uma prova prévia" (1973, p. 52). Desse modo, anteriormente à aplicação do questionário, foi realizado um pré-teste, com a finalidade de melhorar o instrumento e identificar falhas que, porventura, poderiam vir a prejudicar a pesquisa, como questões muito complexas, muito vagas, que exigissem questões complementares para perfeito entendimento, questões desnecessárias, etc. Witt afirma que "[...] pelo pré-teste podemos verificar se as palavras utilizadas são adequadas ao universo a ser pesquisado, se elas são entendíveis e ainda se têm o mesmo significado para todos os indivíduos" (1973, p. 52). A autora menciona também que “[...] o pré-teste não deve ser aplicado na mesma população alvo do estudo definitivo, ou na área do estudo final. Será aplicado em população com características semelhantes à que será utilizada de fato" (1973, p. 55).

Assim, o questionário foi submetido a uma análise crítica, realizada por dois gestores que atuam na área de custos e em empresas industriais localizadas no estado do Rio Grande do Sul. A partir disso, as recomendações para melhoria foram observadas na elaboração da versão final do questionário.

O questionário foi composto por quatro questões que objetivaram definir o perfil dos respondentes e mais oito questões com o intuito de verificar a opinião dos respondentes quanto às críticas aos métodos de custeamento. Essas oito questões 
foram elaboradas com base nas críticas aos métodos de custeamento descritas pelos autores Miranda et al. (2007), Khoury e Ancelevicz (1999), Beuren e Roedel (2002), Frezatti et al. (2009), Pereira Filho e Amaral (1998), Machado (2005), Maher (1997) , Beuren, Souza e Raupp (2004), Martins (2003), Reyhanoglu (2004), Mishra e Vaysman (2001).

O questionário foi enviado aos participantes por meio da ferramenta Googledocs no dia 6 de abril de 2010. A coleta dos dados estendeu-se até o dia 19 de maio de 2010. Para maximizar o retorno dos questionários, ele foi reenviado para a população duas vezes por semana, nas terças e nas quintas-feiras, acompanhado de uma solicitação para seu preenchimento e devolução.

Encerrado o prazo de coleta dos dados, 27 questionários foram preenchidos e caracterizados como passíveis de serem analisados. A análise quantitativa dos dados foi realizada por meio do cálculo do ranking médio, conforme Oliveira (2005). Pelo cálculo do ranking médio, os valores menores que três são considerados discordantes, e os valores maiores que três são considerados concordantes, em uma escala Likert de cinco pontos. O valor exato de três é considerado indiferente ou sem opinião. O cálculo do ranking médio considera uma média ponderada, em que o valor da escala utilizada é multiplicado pela frequência de respostas manifestadas pelos respondentes.

Depois de encontrado o resultado, ele foi dividido pelo número de respondentes, resultando no ranking médio em que a opinião dos respondentes foi classificada. Também foi aplicado o teste estatístico Kruskal-Wallis, com o objetivo de identificar se existia diferença de opinião na amostra, segundo suas características.

\section{Análise do resultados}

A partir desta seção, serão demonstrados e analisados os resultados da tabulação dos dados. Primeiramente, descrever-se-á o perfil dos respondentes. Para a caracterização dos respondentes, foram elaboradas quatro questões que objetivavam apurar a idade, o cargo, o tempo de serviço e o grau de instrução. A caracterização da amostra foi realizada, principalmente, para verificar se, de fato, o questionário fora respondido pelo público alvo da pesquisa.

\subsection{Descrição do perfil da amostra}

A Tabela 1 mostra os resultados da questão que pergunta ao entrevistado a sua idade 
Tabela 1 - Idade dos respondentes

\begin{tabular}{l|c|c}
\hline \multicolumn{1}{c|}{ Idade } & $\begin{array}{c}\text { Número de } \\
\text { respostas }\end{array}$ & $\begin{array}{c}\text { Percentual em relação ao total } \\
(\%)\end{array}$ \\
Entre 20 e 30 anos & 2 & 7,41 \\
Acima de 30 até 40 anos & 9 & 33,33 \\
Acima de 40 até 50 anos & 11 & 40,74 \\
Acima de 50 anos & 5 & 18,52 \\
Total & $\mathbf{2 7}$ & $\mathbf{1 0 0 , 0 0}$ \\
\hline
\end{tabular}

Fonte: elaboração dos autores com base nos dados da pesquisa.

Conforme os dados apresentados na Tabela 1, os respondentes pesquisados concentram-se em uma faixa etária entre 40 e 50 anos (40,74\%). A maior parte dos gestores, $59,26 \%$, tem idade superior a 40 anos, visto que para desempenhar cargo de gestão a experiência de vida é um dos fatores importantes, que somente é acumulada com o passar dos anos.

A segunda questão solicitava ao respondente o cargo ocupado na empresa. Os resultados obtidos são descritos na Tabela 2 .

Tabela 2 - Descrição do cargo dos respondentes

\begin{tabular}{l|c|c}
\hline \multicolumn{1}{c|}{ Cargo } & $\begin{array}{c}\text { Número de } \\
\text { respostas }\end{array}$ & $\begin{array}{c}\text { Percentual em relação } \\
\text { ao total (\%) }\end{array}$ \\
\hline Controller & 5 & 18,52 \\
Gerente administrativo & 4 & 14,81 \\
Diretor & 3 & 11,11 \\
Contador geral & 3 & 11,11 \\
Contador de custos & 2 & 7,41 \\
Analista de custos & 2 & 7,41 \\
Gerente financeiro & 1 & 3,70 \\
Gerente de produção & 1 & 3,70 \\
Coordenador financeiro & 1 & 3,70 \\
Gerente de controladoria & 1 & 3,70 \\
Analista de planejamento e controle & 1 & 3,70 \\
Auditor & 1 & 3,70 \\
Gerente de informações & 1 & 3,70 \\
Supervisor administrativo & 1 & 3,70 \\
Total & 27 & 100,00 \\
\hline
\end{tabular}

Fonte: elaboração dos autores com base nos dados da pesquisa. 
Pelos resultados apresentados na Tabela 2, percebe-se que a maior parte dos respondentes identificou-se como controller, seguido por gerente administrativo, diretor e contador geral. Pelo cargo dos respondentes, percebe-se que o público-alvo da pesquisa foi atingido, revelando que as respostas foram oferecidas por gestores ligados a cargos de direção e gerência, tomadores de decisão.

Os respondentes foram questionados também sobre o tempo de trabalho desempenhado na empresa. Os resultados desse questionamento estão descritos na Tabela 3.

Tabela 3 - Tempo de serviço na empresa

\begin{tabular}{l|c|c}
\hline \multicolumn{1}{c|}{ Tempo de serviço na empresa } & $\begin{array}{c}\text { Número de } \\
\text { respostas }\end{array}$ & $\begin{array}{c}\text { Percentual em relação } \\
\text { ao total }(\%)\end{array}$ \\
\hline Até 3 anos & 3 & 11,11 \\
Acima de 3 até 6 anos & 3 & 11,11 \\
Acima de 6 até 9 anos & 2 & 7,41 \\
Acima de 9 até 12 anos & 5 & 18,52 \\
Acima de 12 anos & 14 & 51,85 \\
Total & 27 & 100,00 \\
\hline
\end{tabular}

Fonte: elaboração dos autores com base nos dados da pesquisa.

Os dados apresentados na Tabela 3 corroboram as informações constantes nas tabelas anteriores. Percebe-se que 70,37\% dos respondentes somam mais de nove anos de trabalho na empresa, ou seja, para desempenhar cargo de gestão é importante conhecer profundamente a empresa, o que exige amplo tempo de trabalho na empresa.

Por fim, na Tabela 4, seguem os resultados da análise do grau de instrução dos respondentes. O nível de instrução de todos foi classificado como ensino superior completo. A Tabela 4 também apresenta os cursos superiores apontados pelos respondentes.

Tabela 4 - Curso superior dos respondentes

\begin{tabular}{l|c|c}
\hline \multicolumn{1}{c|}{ Curso superior } & $\begin{array}{c}\text { Número de } \\
\text { respostas }\end{array}$ & $\begin{array}{c}\text { Percentual em relação } \\
\text { ao total (\%) }\end{array}$ \\
\hline Ciências Contábeis & 13 & 48,15 \\
Administração & 11 & 40,74 \\
Ciências Econômicas & 2 & 7,41 \\
Medicina Veterinária & 1 & 3,70 \\
Total & 27 & 100,00 \\
\hline
\end{tabular}

Fonte: elaboração dos autores com base nos dados da pesquisa. 
Observa-se, pelos resultados apontados na Tabela 4, que a maioria dos sujeitos tem formação superior nos cursos de Ciências Contábeis e Administração. Também se constatou gestores formados em Ciências Econômicas e um formado em Medicina Veterinária.

Em resumo, o perfil da amostra revela na média um gestor com idade superior a 40 anos, atuando em nível gerencial e estratégico, com mais de nove anos de atuação na empresa e formado em Ciências Contábeis ou Administração.

\subsection{Métodos de custeio utilizados nas empresas pesquisadas}

Após a caracterização dos respondentes, na Tabela 5, são apresentados os resultados referentes aos métodos de custeio utilizados nas empresas pesquisadas.

Tabela 5 - Métodos de custeio utilizados pelas empresas

\begin{tabular}{l|c|c}
\hline \multicolumn{1}{c|}{ Método de custeio } & $\begin{array}{c}\text { Número } \\
\text { de respostas }\end{array}$ & $\begin{array}{c}\text { Percentual em } \\
\text { relação ao total (\%) }\end{array}$ \\
\hline Custeio absorção & 13 & 29,55 \\
Custeio pleno & 8 & 18,18 \\
Custeio variável ou custeio direto & 6 & 13,64 \\
Custeio padrão & 5 & 11,36 \\
Custeio unidade esforço de produção & 4 & 9,09 \\
Custeio baseado em atividades & 3 & 6,82 \\
Departamentalização & 2 & 4,55 \\
Custeio baseado em atividades com despesas & 2 & 4,55 \\
Custeio meta & 1 & 2,27 \\
Total & 44 & 100,00 \\
\hline
\end{tabular}

Fonte: elaboração dos autores com base nos dados da pesquisa.

De acordo com o observado na Tabela 5, o método mais utilizado é o custeio absorção, seguido pelo custeio pleno e, em terceiro lugar, pelo custeio variável. Todos os demais métodos foram selecionados pelas empresas.

Em pesquisa realizada por Beuren, Sousa e Raupp (2004, p. 12), do total das empresas pesquisadas, 35 empresas (43\%) posicionaram-se pela utilização do custeio absorção, 23\% pelo custeio direto, e o restante do percentual foi dividido entre os demais sistemas de custeio.

A pesquisa realizada por Almeida e Santos (2007), que investigava as práticas de contabilidade de custos em indústrias paranaenses, demonstrou que $93 \%$ do 
total de empresas pesquisadas (catorze) também adotavam o custeio absorção no processo de gestão.

Totalizou-se 44 observações para os métodos de custeio utilizados pelas empresas. Isso se justifica pelo fato de que uma única empresa pode valer-se de mais de um método de custeio simultaneamente, o que ocorreu em diversas empresas pesquisadas.

\subsection{Percepção das críticas realizadas aos métodos de custeio}

Após a caracterização dos respondentes, a segunda etapa do questionário objetivou verificar a percepção dos respondentes quanto às críticas realizadas aos métodos de custeio por meio de oito questões.

Os métodos de custeio foram divididos em três grupos. No primeiro grupo, foram enquadrados os métodos de custeio conhecidos como departamentalização, centro de custos, custeio absorção e absorção pleno. Foram identificadas três principais críticas em relação aos métodos utilizados. O grau de concordância do respondente para cada crítica foi apurado considerando uma escala Likert de cinco níveis. Os resultados referentes às críticas relacionadas aos métodos de custeio classificados no primeiro grupo são apresentados na Tabela 6 .

Tabela 6 - Percepção das críticas atribuídas aos métodos de custeio departamentalização, centro de custos, custeio absorção e absorção pleno

\begin{tabular}{|c|c|c|c|c|c|c|}
\hline \multirow{2}{*}{ Críticas } & \multicolumn{5}{|c|}{ Frequência } & \multirow{2}{*}{$\mathrm{RM}^{*}$} \\
\hline & 1 & 2 & 3 & 4 & 5 & \\
\hline $\begin{array}{l}\text { Prejudica a tomada de decisão sobre aceitar ou não uma } \\
\text { encomenda, produzir ou comprar determinado componente, etc. }\end{array}$ & 6 & 4 & 0 & 14 & 3 & 3,14 \\
\hline $\begin{array}{l}\text { Prejudica a tomada de decisão, pois envolve a distribuição arbitrária } \\
\text { dos demais gastos de fabricação, como aluguel, depreciação, } \\
\text { material de limpeza, etc. }\end{array}$ & 1 & 9 & 0 & 16 & 1 & 3,25 \\
\hline $\begin{array}{l}\text { Os custos apurados são influenciados por um maior ou menor } \\
\text { volume de produção. }\end{array}$ & 1 & 0 & 0 & 0 & 26 & 4,85 \\
\hline
\end{tabular}

Fonte: elaboração dos autores com base nos dados da pesquisa.

${ }^{*} \mathrm{RM}=$ ranking médio.

Pelos resultados apontados na Tabela 6, percebe-se que os respondentes posicionaram-se de acordo com as críticas atribuídas aos métodos de custeio. A crítica mais reconhecida dentre as três foi a que menciona que os custos apurados são influenciados por um maior ou menor volume de produção. Além do reconhecimento 
dessa crítica, o reconhecimento das demais leva à conclusão de que os respondentes têm boas noções de custo e, provavelmente, não levam em consideração a utilização desses métodos de custeio para a tomada de decisão.

Comparando-se os resultados da Tabela 6 com os apurados na Tabela 5, percebe-se que mesmo com os profissionais reconhecendo as críticas atribuídas aos métodos de custeio conhecidos como departamentalização, centro de custos, custeio absorção e absorção pleno, esses mesmos métodos correspondem àqueles utilizados em $77,78 \%$ das empresas pesquisadas.

$\mathrm{O}$ fato de os gestores reconhecerem as críticas aplicadas ao sistema de custeio absorção e continuar a utilizá-lo já chamou a atenção de pesquisadores.

Vancil destaca que:

[...] a alocação de custos já vem de longa data um assunto controverso na literatura de economia e contabilidade. Enquanto pesquisadores economistas e contadores tipicamente recomendam preços de custos marginais na alocação dos recursos da empresa, as empresas usualmente vão contra a essa recomendação e continuam na alocação dos custos (1978 apud WHANG, 1989, p. 1264).

A esse respeito, Jordan (1988 apud WHANG 1989, p. 1265) aduzem que “[...] alocação de custos é um modo para motivar todos os participantes (gerente de recursos e usuários) para otimizar a rentabilidade da organização além de um conjunto de oportunidades que o principal pode não ser capaz de identificar".

Segundo Beja e Zang:

[...] sobre a perspectiva de que a empresa é um time descentralizado, a alocação de custos serve como um sistema de informação que avalia a rentabilidade de diferentes atividades divisionais que estão correlacionadas através de um resultado em comum/componente de custo (1986 apud WHANG, 1989, p. 1265).

Percebe-se que essa preocupação já vem de longa data. Já que é possível concluir que existiria uma motivação pessoal de parte da gestão da empresa em manter um sistema de custos com arbitrariedade. A arbitrariedade no sistema de custos auxiliaria na resolução de problemas de agência dentro da empresa. Um exemplo disso pode ocorrer quando o diretor de uma empresa utiliza critérios arbitrários de distribuição de custos com o objetivo de diminuir a rentabilidade de determinada divisão, evitando com isso que os funcionários daquela divisão utilizem o pretexto da boa rentabilidade para barganhar aumentos de salário.

Desse modo, a seguir, serão abordadas as críticas relacionadas ao método de custeio direto ou variável. A Tabela 7 demonstra os resultados da percepção das críticas realizadas a esse método de custeio. 
Tabela 7 - Percepção das críticas atribuídas ao método de custeio direto ou variável

\begin{tabular}{|c|c|c|c|c|c|c|}
\hline \multirow{2}{*}{ Críticas } & \multicolumn{5}{|c|}{ Frequência } & \multirow{2}{*}{$\mathrm{RM}^{*}$} \\
\hline & 1 & 2 & 3 & 4 & 5 & \\
\hline $\begin{array}{l}\text { Método comprometido, pois não há como classificar de modo claro } \\
\text { quais são os custos fixos e variáveis. }\end{array}$ & 4 & 5 & 4 & 11 & 3 & 3,14 \\
\hline Atende somente a necessidades de informação para um curto prazo. & 2 & 5 & 4 & 9 & 7 & 3,51 \\
\hline
\end{tabular}

Fonte: elaboração dos autores com base nos dados da pesquisa.

${ }^{*} \mathrm{RM}=$ ranking médio.

Pelos dados apresentados na Tabela 7, comprova-se que as críticas encontradas na literatura sobre os métodos de custeio também são reconhecidas na prática pelos gestores pesquisados. Ambas as críticas posicionaram-se na posição de concordância. Da mesma forma que ocorreu com a questão anterior, embora as críticas tenham sido reconhecidas, elas não se constituem em empecilho para a utilização dos métodos.

Do total das empresas pesquisadas, $18,52 \%$ utilizam o método do custeio direto ou variável. Portanto, destaca-se que as críticas são encaradas como uma limitação, mas não como um motivo para a não utilização do método.

Abordadas as críticas referentes ao método de custeio direto ou variável, serão abordadas as críticas relacionadas ao método de custeio baseado em atividades. A Tabela 8 apresenta os resultados da percepção das críticas realizadas a esse método de custeio.

Tabela 8 - Percepção das críticas atribuídas ao método de custeio baseado em atividades

\begin{tabular}{|c|c|c|c|c|c|c|}
\hline \multirow{2}{*}{ Críticas } & \multicolumn{5}{|c|}{ Frequência } & \multirow{2}{*}{$\mathrm{RM}^{*}$} \\
\hline & 1 & 2 & 3 & 4 & 5 & \\
\hline $\begin{array}{l}\text { No custeio baseado em atividades, os critérios de distribuição dos } \\
\text { gastos de difícil alocação, como aluguel, depreciação, etc., são } \\
\text { aleatórios. }\end{array}$ & 1 & 7 & 5 & 9 & 5 & 3,37 \\
\hline $\begin{array}{l}\text { O custeio baseado em atividades é muito complexo, de difícil } \\
\text { manutenção e custoso. }\end{array}$ & 0 & 3 & 4 & 11 & 9 & 3,96 \\
\hline $\begin{array}{l}\text { É inviável sua aplicabilidade devido ao grande número de atividades } \\
\text { na empresa. }\end{array}$ & 4 & 3 & 4 & 10 & 6 & 3,40 \\
\hline
\end{tabular}

Fonte: elaboração dos autores com base nos dados da pesquisa.

${ }^{*} \mathrm{RM}=$ ranking médio.

Analisando os resultados encontrados na Tabela 8, percebe-se que todas as críticas testadas para o método do custeio baseado em atividades foram reconhecidas pelos respondentes. A crítica que afirma que o custeio $\mathrm{ABC}$ é muito complexo, de difícil manutenção e custoso foi a que obteve maior índice de aprovação. 
Entretanto, do total de respondentes, $18,52 \%$ deles afirmaram que utilizam esse método em suas empresas.

Percebe-se que todas as críticas realizadas aos métodos de custeio foram reconhecidas pelos respondentes. Igualmente, nenhuma das empresas declarou que não utiliza algum desses métodos de custeio na gestão. Sendo assim, conclui-se que, apesar das críticas, elas não se constituem, na maioria dos casos, em impedimento para a utilização de determinado método, mas, sim, em uma limitação quanto à sua utilização.

Para melhor análise dos dados, foram analisadas as variáveis curso de formação superior, idade e tempo de atuação para verificar se são dados estatisticamente diferentes do grupo geral. Utilizou-se o teste Kruskal-Wallis ao nível de significância de 5\%. Os resultados são demonstrados na Tabela 9.

Tabela 9 - Valor Asymp. Sig. para o teste Kruskal-Wallis

\begin{tabular}{c|c|c|c}
\hline Questões & Curso & Idade & Tempo \\
\hline Q1 & 0,363 & 0,252 & 0,206 \\
Q2 & 0,775 & 0,370 & 0,439 \\
Q3 & 0,676 & 0,320 & 0,646 \\
Q4 & 0,088 & 0,952 & 0,749 \\
Q5 & 0,305 & 0,409 & 0,429 \\
Q6 & 0,691 & 0,813 & 0,669 \\
Q7 & 0,603 & 0,829 & 0,288 \\
Q8 & 0,630 & 0,493 & 0,475 \\
\hline
\end{tabular}

Fonte: elaboração dos autores com base nos dados da pesquisa.

Conforme consta na Tabela 9, os resultados do teste sugerem que a opinião da amostra, em relação às questões de pesquisa, não difere entre as variáveis curso superior, idade e tempo de serviço.

\section{Considerações finais}

Mudanças no ambiente em que as empresas estão inseridas são naturais e inegáveis, e exigem de seus gestores um novo posicionamento gerencial, que envolva repensar ferramentas utilizadas na gestão dos custos. Naturalmente, correntes teóricas traçam críticas aos sistemas de custeio, evidenciando suas fraquezas. 
Considerando esse contexto, esta pesquisa objetivou verificar com gestores de médias e grandes empresas industriais do estado de Santa Catarina se eles reconhecem as críticas encontradas na literatura sobre os métodos de custeio. A partir da análise das respostas apresentadas, verificou-se que todas as críticas testadas na pesquisa foram reconhecidas pelos respondentes. Paralelamente a isso, percebe-se que as empresas pesquisadas utilizam métodos de custeamento. Destaca-se como mais utilizado o método de custeio absorção, também um dos mais criticados no meio acadêmico. Desse modo, verifica-se que as críticas traçadas aos métodos não constituem impedimentos para sua utilização, configurando-se apenas como limitações.

Entretanto, destaca-se que a larga utilização do sistema de custeio por absorção aliada ao conhecimento das limitações desse método pelos gestores induz a avaliar a possibilidade de existirem motivos determinantes para a preferência pelo método absorção, possivelmente ligados a problemas de agência.

Recomenda-se pesquisas futuras com o objetivo de investigar como os gestores administram as limitações dos métodos de custeio durante a execução das atividades gerenciais. Também cabe investigar os motivos que levam os gestores a continuar utilizando determinados métodos de custeio em detrimento de outros que se mostram superiores tecnicamente. Finalizando, destaca-se que os resultados desta pesquisa referem-se apenas à amostra do estudo e, portanto, não podem ser generalizados. 


\title{
Evaluation of criticism reported in the literature to costing methods: perception of managers from middle and large industrial companies in Santa Catarina
}

\begin{abstract}
Changes in the business environment require from cost accounting a new position in order to meet the needs of managers. Costing methods that until recently were considered suitable, are now considered outdated because they are not suited to the current business environment. The overall objective of this research is to check with managers from middle and large industrial companies in the state of Santa Catarina, if they recognize the criticism in the literature on costing methods. To this end, the research was characterized as descriptive, quantitative and survey. The results show that, in general, the criticism attributed to the costing methods are recognized by the managers. Allied to this, it also realizes that even though the criticisms are acknowledged, they do not constitute an impediment to the use of the method, but rather a limitation.
\end{abstract}

Keywords: Criticism. Costing methods. Costs.

\section{Evaluación de la crítica reportada en la literatura para métodos de costeo: percepción de los gerentes de empresas industriales medianas y grandes en Santa Catarina}

\section{Resumen}

Los cambios en el entorno empresarial requieren de la contabilidad de costos una nueva posición con el fin de satisfacer las necesidades de los administradores. Métodos de costeo que hasta hace poco se consideraban adecuados, ahora se consideran obsoletos, ya que no son adecuados para el entorno empresarial actual. El objetivo general de esta investigación es comprobar con los gerentes de medios y grandes empresas industriales en el estado de Santa Catarina, si reconocen la crítica en la literatura sobre métodos de costeo. Para este fin, la investigación se caracterizó como descriptiva, cuantitativa y encuesta. Los resultados muestran que, en general, la crítica asignada a los métodos de costeo son reconocidas por los gerentes. Junto a esto, también se da cuenta de que a pesar de que se reconocen las críticas, que no constituyen un impedimento para el uso del método, sino más bien una limitación.

Palabras clave: Crítica. Métodos de Costeo. Costos. 


\section{Nota}

1 Filosofia gerencial que procura não somente eliminar os desperdícios, mas também disponibilizar o componente que será utilizado no processo produtivo no lugar e hora certos (MARTINS; LAUGENI, 2015).

\section{Referências}

ALMEIDA, Lauro Brito de; SANTOS, Ademilson Rodrigues dos. Práticas de contabilidade de custos: uma investigação nas indústrias paranaenses. Sociedade, Contabilidade e Gestão, Rio de Janeiro, v. 2, n. 1, 1.ำ sem. 2007.

BABAD, Y. M.; BALACHANDRAN, B. V. Cost driver optimization in activity-based costing. The Accounting Review, Chicago, v. 68, n. 3, p. 563-575, jul. 1993.

BEBER, Sedinei J. N. et al. Princípios de custeio: uma nova abordagem. In: ENCONTRO NACIONAL DE ENGENHARIA DE PRODUÇÃO, 24, 2004, Florianópolis. Anais... Florianópolis: Abepro, 2004.

BEUREN, Ilse Maria; ROEDEL, Ari. O uso do custeio baseado em atividades - ABC (Activity Based Costing) nas maiores empresas de Santa Catarina. Revista Contabilidade \& Finanças USP, São Paulo, n. 30, p. 7-18, set./dez. 2002.

BEUREN, Ilse Maria; SOUSA, Marco Aurélio Batista de; RAUPP, Fabiano Maury. Um estudo sobre a utilização de sistemas de custeio em empresas brasileiras. In: CONGRESSO INTERNACIONAL DE CUSTOS, VII, 2004, Punta del Este, Uruguay. Anais... Punta del Este: CIC, 2004. Disponível em: <http://www.iem.efei.br/edson/download/Congresointernacional2004/110 sistemasdecuste $>$. Acesso em: 30 abr. 2010.

BORNIA, A. C. Análise gerencial de custos: aplicação em empresas modernas. Porto Alegre: Bookman, 2002.

COLAUTO, R. D.; BEUREN, I. M. Coleta, análise e interpretação dos dados. In: BEUREN, I. M. (Org.). Como elaborar trabalhos monográficos em contabilidade: teoria e prática. São Paulo: Atlas, 2009. p. 117-143.

COGAN, Samuel. Activity-based Costing $(A B C)$ : a poderosa estratégia empresarial. São Paulo: Pioneira, 1994.

FREZATTI, F. et al. Controle gerencial: uma abordagem da contabilidade gerencial no contexto econômico, comportamental e sociológico. São Paulo: Atlas, 2009.

GIL, Antônio Carlos. Métodos e técnicas de pesquisa social. 5. ed. São Paulo: Atlas, 1999.

HAIR JR., Josep F. et al. Fundamentos de métodos de pesquisa em administração. Porto Alegre: Bookman, 2005.

KHOURY, Carlos Y.; ANCELEVICZ, Jacob. A utilização do sistema de custos ABC no Brasil. Revista de Administração de Empresas, São Paulo, v. 39, n. 1, p. 55-63, jan./mar. 1999.

LEDERER, A. L. et al. Information system cost estimating: a management perspective. Miss Quarterly, Minnesota, v. 14, n. 2, p. 159-176, jun. 1990. 
MACHADO, Débora Gomes. Análise das relações entre a gestão de custos e a gestão do preço de venda: um estudo das práticas adotadas por empresas industriais conserveiras estabelecidas no RS. 2005. 191 f. Dissertação (Mestrado em Contabilidade) - Universidade do Vale do Rio dos Sinos, São Leopoldo, 2005.

MAHER, Michael. Cost accounting: creating value for management. 5. ed. Chicago: Irwin, 1997 . MARTINS, E. Contabilidade de custos. São Paulo: Atlas, 2003.

MARTINS, P. G.; LAUGENI, F. P. Administração da produção. 3. ed. São Paulo: Saraiva, 2015. MATZ, Adolf; CURRY, Othel J.; FRANK, George W. Contabilidade de custos. São Paulo: Atlas, 1987.

MIRANDA, G. J. et al. Custeio ABC no ambiente hospitalar: um estudo nos hospitais universitários e de ensino brasileiros. Revista Contabilidade e Finanças, São Paulo, v. 18, n. 44, p. 33-43, maio/ago. 2007.

MISHRA, B.; VAYSMAN, I. Cost-System choice and incentives-traditional vs. activity-based costing. Journal of Accounting Research, Chicago, v. 39, n. 3, p. 619-641, Dec. 2001.

NAKAGAWA, M. Gestão estratégica de custos: conceitos sistemas e implementação. São Paulo: Atlas, 2000 .

OLIVEIRA, Luciel Henrique de. Exemplo de cálculo de ranking médio para Likert. Notas de aula: metodologia científica e técnicas de pesquisa em administração. Dissertação (Mestrado em Administração e Desenvolvimento Organizacional) - Programa de Pós-Graduação em Administração, Faculdade Cenecista de Varginha, Varginha, 2005.

PEREIRA FILHO, A. D.; AMARAL, H. F. A contabilidade de custos como instrumento de informação gerencial - um enfoque no sistema de custeio ABC. Contabilidade Vista \& Revista, Belo Horizonte, v. 9, n. 2, p. 3-14, jun. 1998.

PEREZ JR., J. H.; OLIVEIRA, L. M. de; COSTA, R. G. Gestão estratégica de custos. São Paulo: Atlas, 2001.

RAUPP, F. M.; BEUREN, I. M. Metodologia da pesquisa aplicável às ciências sociais. In: BEUREN, I. M. (Org.). Como elaborar trabalhos monográficos em contabilidade: teoria e prática. São Paulo: Atlas, 2009. p. 76-96.

REYHANOGLU, M. Activity-based costing system: advantages and disadvantages. Social Science Research Network. 2004. Disponível em <http://papers.ssrn.com/sol3/papers.cfm?abstract_ $\mathrm{id}=644561>$. Acesso em: 31 maio 2010.

RECKZIEGEL, V.; SOUZA, M. A.; DIEHL, C. A. Práticas de gestão de custos adotadas por empresas estabelecidas nas regiões noroeste e oeste do Estado do Paraná. Revista Brasileira de Gestão de Negócios, São Paulo, v. 9, n. 23, p. 14-27, jan./abr. 2007.

RICHARDSON, R. J. Pesquisa social: métodos e técnicas. São Paulo: Atlas, 1989.

ROESCH, Sílvia M. A. Projetos de estágio e de pesquisa em administração. São Paulo: Atlas, 1999.

SOUZA, M. A.; LISBOA, L. P.; ROCHA, W. Práticas de contabilidade gerencial adotadas por subsidiárias brasileiras de empresas multinacionais. Revista Contabilidade e Finanças - USP, São Paulo, n. 32, p. 40-57, maio/ago. 2003.

WHANG, S. Cost allocation revisited: an optimality result. Management Science, Catonsville, v. 35, n. 10, p. 1264-1273, Oct. 1989.

WITT, Aracy. Metodologia de pesquisa. São Paulo: Resenha Tributária, 1973. 